\title{
Scenario-based designing of closed-loop supply chain with uncertainty in returned products
}

\author{
Iman Ghasemian Sahebi ${ }^{\mathrm{a}}$, Behzad Masoomi ${ }^{\mathrm{b}}$, Shahryar Ghorbanic ${ }^{\mathrm{c}}$ and Tanyeri Uslu ${ }^{\mathrm{d}}$
}

${ }^{a}$ Lecturer at University of Qom, Department of Management, Qom, Iran

${ }^{b}$ PhD student in Operation Management, Department of Management, Islamic Azad University, Firoozkooh Branch, Tehran, Iran

${ }^{c}$ Phd Student in Management and Business Administration Programme, Graduate School of Social Sciences, Istanbul Gedik University, Turkey

${ }^{d}$ Assist. Prof. Dr. Tanyeri Uslu, Department of Business Administration, Faculty of Economic, Administrative and Social Sciences, Istanbul Gedik University, Turkey

\begin{tabular}{l}
\hline C H R O N I C L E \\
\hline Article history: \\
Received December 10, 2018 \\
Received in revised format: \\
March 29, 2019 \\
Accepted April 14, 2019 \\
Available online \\
April 14, 2019 \\
\hline Keywords: \\
Closed-Loop Supply Chain \\
Reverse Logistics \\
Scenario Planning \\
Steel Industry
\end{tabular}

\begin{abstract}
A B S T R A C T
Closed-loop supply chain management is an effective and efficient solution for a set of activities to retrieve a product from a customer and improve its value or to dispose it. Today, designing and planning a closed-loop chain is an inevitable but difficult task. In this research, a scenariobased modeling approach is presented by considering both forward and reverse flows as a closedloop supply chains in steel industry. The proposed study also develops a multi-product and multiperiod model based on a mixed integer linear programming (MILP) approach for profit maximization. The study also considers uncertainty in the amount of raw material, processing, storage and distribution of several products flow. Uncertainty is associated with the quantity and quality of the products in the reverse flow, which are directly affected by customers and sorting centers, respectively. Finally, the model is deployed in Steel industry with real data. The results show that by increasing the quality level of returned products the need for raw materials is reduced and the total profit of the supply chain is increased.
\end{abstract}

\section{Introduction}

Companies connect their systems to the sustainable processes due to external forces such as environmental regulations, improvement operations, profitability, customer awareness and social responsibilities. Returned product planning is one of the most important sustainable processes, designed with a management approach called reverse logistics (Soleimani et al., 2017). Consumed or disposed products are gathered from consumers by companies with the help of reverse logistics for the purpose of recycling to enhance sustainability, overall profitability and productivity (Temur \& Balot, 2012). The necessity of more investigation on the reverse supply chain becomes more important with the development of industries and reduction of initial resources, enhancing the cost of supplying resources and environmental requirements (Govindan \& Soleimani, 2017). Also, new and guaranteed business opportunities for different industries have been created using the environmental considerations such as returned management, waste management, pollutants management, recycling and reducing pollution, along with cost-effectiveness from lifecycle extension. Many companies and industries in advanced countries have begun research in this field over the past two decades, and the issues including policies

\footnotetext{
* Corresponding author. Tel.: +989112267648

E-mail address: masoomibehzad4@gmail.com (B. Masoomi)

(C) 2019 by the authors; licensee Growing Science, Canada. doi: $10.5267 /$ j.dsl.2019.4.003
} 
for returned product with quick response times, customer-defined services, and more emphasis on returned management, transformation and restoration of expired goods have been raised in this regard (Cannella et al., 2016). Accordingly, the return management has recently been considered as one of the logistics chain issues. The return management issue has been increasingly important so that nowadays, it is regarded as an element of strategic business (Masoudi, 2011). Therefore, it can be said that a reverse supply chain needs product return flow management to obtain the stability and profitability (Ene \& Ozturk, 2017). Beside this, different approaches have been applied to cope with uncertainty, including stochastic programming such as possibility distribution, stochastic constraints, and two-stage stochastic programming (Jeihoonian et al., 2017), fuzzy logic (type-1\&2 fuzzy approaches), distance planning approaches (considering the distance values for uncertain parameters) (Amin et al., 2017), Chaos theory and a combination of mentioned approaches (Amin \& Baki, 2017). In addition, the scenario-based approaches can be applied separately or by solution method of different nondeterministic approaches. Most research efforts on supply chain designing and planning have considered the non-deterministic parameters in the forward flow (Kadambala et al., 2017), but combining the backward flow caused to appear several new sources of uncertainty in return times, the quality and the quantity of returns, etc. (Akcali \& Cetinkaya, 2011). It is worth noting that, most of the traditional supply chains have been operating only as forward all over the world, especially Iran steel supply chain in recent years is no exception. The steel recycling industry, as an important industry in the country, collects scrap, iron and steel, and makes them reusable in the industry by melting and converting them into ingots. The ingots, produced in the casting workshops, are turned into valuable parts, and in this way, the scrap and iron and steel waste are re-entered into the consumption cycle (Cannella et al., 2016).

Based on what was said above, this paper aims to design a closed-loop supply chain by determining the number and place of network nodes (including factory, warehouse, customer, collection centers, and disposal centers) at a time horizon. In addition, the best possible planning has been examined for supply, production, transportation, storage, and collection at various time periods. The final goal is to maximize the chain's profit. In this paper, according to the above-mentioned cases, the steel industry is an appropriate option for reviewing as the case study, because the quality level of the collected scrap iron affects the product and it is necessary to make changes in final product in order to convert each level to the desired steel.

\section{Research Background}

The study of the closed-loop supply chains has become the main branch of the supply chain literature in the last decade, and more attention has been spent to understand, to manage and to improve the structure of these types of supply chains (Adenso-Diaz et al., 2012; He, 2015). In other words, this kind of supply chain focuses on retrieved products from customers and improves their added values by reusing the entire product or some modules, parts, and components (Dowlatshahi, 2010). The forward flow of materials/products, mainly from suppliers to producers, distributors, retailers and ultimately, customers is what is happening in the traditional flow of goods, and industry leaders emphasize on it. However, there is another important flow in supply chains of many industries that are inversely shaped, so that products flow from lower levels of supply chain to upper levels. Hence, designing and planning a closed-loop chain is an inevitable but difficult issue. On the other hand, the number of returned products plays an important role to create a profitable reverse chain (Soleymani et al., 2014). The increasing and constantly changing requirements of the customers are some of the main challenges according to its significant effect on the efficiency of the production system (Gupta \& Marans, 2003). Therefore, as Papageorgio (2009) pointed out, the need to understand the source of uncertainty has become an important issue. The optimization approaches will be very useful which consider uncertainty, although will lead to very large models in the uncertainty environment according to many parameters. In Sahinidis (2004) and Li and Ierapetritou (2008), it can be seen the optimization approaches to face with uncertainty in the structure and management of organizations and their 
processes. Most articles on uncertainty modeling focus on re-production and inventory planning, while the quality of returned materials has a significant effect on costs. This has been shown in the research of Denizen et al. (2010) where they focused on reproduction planning by designing a linear programming. Also, strategic horizon of supply chain design will intensify the effect of uncertainty on issues. In addition, Fleishman et al. (2016) stated that because controlling and estimating the value and quality of returned products is difficult, this issue becomes more important in the reverse supply chain. The importance of considering uncertainty caused the researchers show non-deterministic parameters in designing the supply chain network (Gaur et al, 2017). Table 1 illustrates the important research in field of closed-loop supply chain designing.

\section{Table 1}

Recent studies considering uncertainty in CLSC designing Solution Method Parameters

\begin{tabular}{|c|c|c|c|c|c|c|c|c|c|c|c|c|c|c|}
\hline & & Iutio & Not! & & & & & & & ene & & & & \\
\hline 当 & $\underset{\mathrm{Z}}{\stackrel{\mathrm{Z}}{\mathrm{Z}}}$ & $\begin{array}{l}\text { T. } \\
\underset{\mathcal{N}}{\mathbb{N}}\end{array}$ & 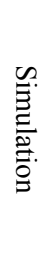 & $\Omega$ & 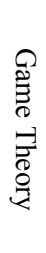 & 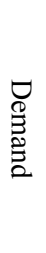 & 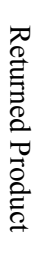 & 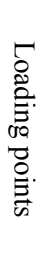 & 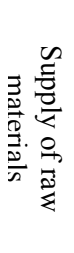 & 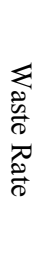 & 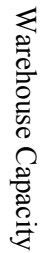 & 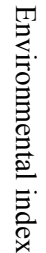 & $\stackrel{7}{\overparen{d}}$ & 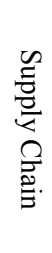 \\
\hline
\end{tabular}

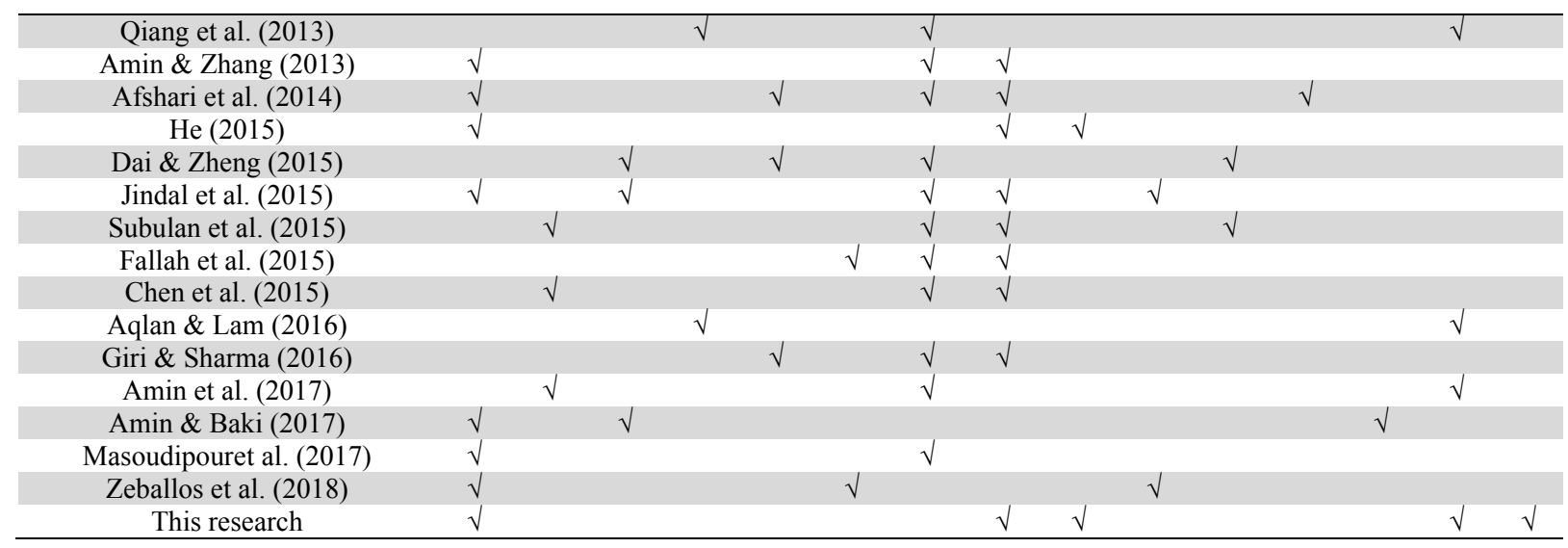

As the literature represents, mixed integer linear programming (MILP) is one of the most common solution methods. These models vary from a single-product model to a multi-product model or multiobjective model (Darbari et al., 2017). For the subject of the uncertainty, optimization techniques have been applied in a MILP framework, including interval programming (Özceylan et al., 2017), Fuzzy programming (Vahdani et al., 2013), stochastic programming (Farrokh et al., 2018) and so on. Pishvaee and Rabbani (2011) provided a robust optimization model for uncertainty on input data in the issues of designing the closed-loop supply chain. Vahdani et al. (2013) provided a reliable network of facilities in closed-loop supply chain with the uncertainty that have used a novel interactive hybrid methodology to solve their proposed model. Chen and Chang (2006) paid attention to the supply chain model with fuzzy parameters and chose a solution method that could calculate the fuzzy value of the goals. Articles with a stochastic programming approach have reviewed closed loop supply chain (CLSC) designing with uncertainty. Salema et al. (2007) proposed the MILP model for designing a single-period, singleproduct reverse logistics network with limited capacity and uncertainty in demand and returned product. Lee and Dong (2009) provided a two-stage stochastic programming model for designing a multi-period network. Since the mathematical optimization techniques are limited in size and complexity, most authors have used meta-heuristic algorithms based on simulated annealing approach (Mohammed et al., 2017). Amin and Zhang (2013) provided a randomized mixed integer linear programming model for a single-period, multi-product CLSC designing that included several factories, collection centers, and demand markets. This model considers demand and returned products with uncertainty parameters. Cardoso and Barbosa Povoa (2013) provided an optimization model for CLSC 
and it reviewed developing the capacity and dynamic transportation in uncertainty situations in product demand. Ghassemi et al. (2018) investigated the configuration of a closed-loop supply chain network, which involves suppliers, a single manufacturer, customers, collection/disassembly centers, disposal centers, a single recovery center and subcontractors. Alamdar et al. (2019) provided a stochastic model of a CLSC with one risk-averse manufacturer, one risk-averse retailer and one risk-averse third party is developed. According to the results, the third party-led model has better performance than manufacturer-led model.

\section{Problem Definition}

A supply chain has 3 major process: 1) production and warehousing, 2) transportation and distribution, and 3) re-production where one or more entities can be achieved in each of these processes: factories, warehouses, distribution centers, customers, collection centers and recycling centers. In each of these facilities, several products and materials can be transported and transformed, simultaneously. This paper has considered five entities: factory, warehouse, costumer, recycling centers and disposal centers. Traditionally, in supply chain models, it is assumed that customers exist in their place where their demand has to be met. In this model, there is also a set of customers with demand and return, but with the difference that customers may be selected or not for membership in the supply chain, and even if they choose, only part of their demand be may be met. The penalty cost is imposed on customers who are not selected at all and customers who are not satisfied with a part of their demands. In the distribution section, the customer demand is met through warehouses, which can do additional work on the product. Transporting costs and warehousing costs occur in this section. Returned products are gathered in the collection centers. After the assembly and inspection activities, some of the components and materials are returned to the factories that are suitable for reuse. Other parts, which are not in good condition, are sent to disposal centers. The model assumptions are as follows:

$\checkmark$ New and re-manufactured products are not recognizable,

$\checkmark$ Supply of new products has a lower and upper bound,

$\checkmark$ All facilities have a maximum capacity that can store the product,

$\checkmark$ The returned product rate is a portion of the supplied products,

$\checkmark$ Travel time is defined as the unit number of the short-term time to move a product from its origin to the destination and is modeled between different levels of the chain,

$\checkmark$ The time of product transforming and consuming is considered as minimum unit number of the short-term time where the product is produced (per facility) or consumed (per customer),

$\checkmark$ The cost of return products will different based on their quality.

\section{Model Designing}

We consider a supply chain $\mathrm{G}=(\mathrm{V}, \mathrm{A})$ with a set of nodes (V) and a set of vectors (A) with $n$ level. $V$ can be defined as follow:

$V=\bigcup_{i=1}^{n} V_{i} \quad, V_{i} \bigcap V_{j}=\varnothing$

where $A_{i}=V_{i} \equiv V_{i+1}, V_{i}$ is a subset of nodes which belongs to the level $n$. Consider there is no need to connect $\mathrm{V}_{\mathrm{t}}$ to all nodes of $\mathrm{V}_{\mathrm{t}+1}$, and therefore $\equiv$ it will only represent potential connections. As a result: $A=\bigcup_{i=1}^{n-1} A_{i}, A_{i} \cap A_{j}=\varnothing$

Another mentioned condition in this model is a multi-product supply chain. Therefore, $M$ is considered as a product set, and $\overline{A_{l}}=M_{i} \equiv A_{i}$ will be the flow-product pair as a subset extension of the vectors. Also, $M$ is defined as A:

$M=\bigcup_{i=1}^{n} M_{i} \cdot M_{i} \bigcap M_{j}=\varnothing$

There are two product categories for each node (input and output products) which are determined based on the place of the node at the beginning or at the end of the vector. Therefore, two subsets of nodes 
are defined, one for input products $\widehat{V}_{i}$ and one for output products $\widehat{V}_{j}$. As a result, the supply chain structure can be defined as a graph $\bar{G}=(V \cdot \bar{A})$ where $\mathrm{V}$ is a set of all entities and $\bar{A}=\bigcup_{i=1}^{n-1} \bar{A}_{i}$ is a set of extended vectors, for example, a set of products - flow pairs. The closed-loop supply chain structure is determined in the design stage, where the decision is made whether create or not the entities. This decision is made for a time period. The planning stage includes shorter times. Two-time scales are considered during the time period. A longer time (macro) is used to divide the time period which is considered as demand and returned values and a shorter time (micro), which allows for more detailed planning to determine demand and returned values. For example, in a 5-year period, the macro-scale is considered to be 1 year, and then it is divided into six-month intervals (micro). Consider $t \epsilon T$ as a member of the macro-time set and $t \in T^{\prime}$ as a member of the micro-time set. For each $t \in T$, it may include $n$ of $T$. In order to create a relationship between two-time scales, a function is defined that relates a time unit to the time unit in the past. This function is required when an action begins in the chain at a time period and continues until the next period. Consider $t \epsilon T$ and $t \in T$, suppose $(\mathrm{t}, \hat{t})$ are the current moment. Now, we want to relate the current time with time at $\tau$ micro-time before. The return function $\gamma$ is defined as follows:

$\gamma\left(t . t^{\prime}-\tau\right)=\left\{\begin{array}{c}\left(t . t^{\prime}-\tau\right) \quad \text { if } t^{\prime}-\tau \geq 0 . \\ \left(t-\omega . \omega n+t^{\prime}-\tau\right) \quad \text { if } t^{\prime}-\tau<0^{\wedge} t \geq \omega\end{array}\right.$

where $\omega \in \mathrm{Z}$ is the smallest integer larger or equal to $\omega=\left[\frac{\tau-\hat{t}}{n}\right]$ and $n=[\bar{T}]$.

As mentioned, the supply chain has a 5-node that in following we will provide required definitions. The sets are one of the most important features of this model that make it possible to define the overall structure of the network. Each node of the supply chain is defined by an entity (e.g., factory, warehouse, customer, etc.). Thus, the set of nodes $V$ is divided into subsets that each refer to a specific node. Also, no entity can belong to two levels (subsets).

$I_{f}$ : potential points for building factory, $i \in I_{f} \subseteq V$

$I_{c}$ : potential points of customer, $i \in I_{c} \subseteq V$

$I_{d}$ : potential points for building recycling centers, $i \in I_{d} \subseteq V$

$I_{w}$ : potential points for building warehouse, $i \in I_{w} \subseteq V$

$I_{o}$ : potential points for building disposal centers, $i \in I_{o} \subseteq V$

Entity $Y_{S}$ is the supplier of raw materials for $\mathrm{I}_{\mathrm{f}}$ which it provides the slack of returned raw material. Here, the assumption is that the cost of transportation and are zero from this entity to the factories: $Y_{s} \subseteq$ $V$. The set of $I=I_{f} \cup I_{w} \cup I_{d}$ includes all entities that will have a fixed cost if they are opened or used. The customers may also be selected or not as a part of network, which is not considered a fixed cost for these states. The entities and products are related to each other. Therefore, developed entities are defined as product-entity pairs. Two sets must be defined differently according to that two entities in two sequential levels may be related to a product. So, consider the subsets of $M$ that each of them refers to a different product:

$M_{f}$ : output products from factories, $m \in M_{f} \subseteq M$

$M_{c}$ : output products from customers, $m \in M_{c} \subseteq M$

$M_{s}$ : output products from supplier, $m \in M_{S} \subseteq M$

$M_{w}$ : output products from warehouses, $m \in M_{w} \subseteq M$

$M_{d}$ : output products from separation centers, $m \in M_{d} \subseteq M$

The developed entities are defined as follow sets:

$$
\begin{aligned}
\breve{V}_{d} & =\left\{(m . i): m \in M_{d} \wedge i \in I_{d}\right\} \\
\breve{V}_{s} & =\left\{(m . i): m \in M_{s} \wedge i \in I_{s}\right\} \\
\breve{V}_{d} & =\left\{(m . i): m \in M_{d} \wedge i \in I_{d}\right\}
\end{aligned}
$$

$$
\breve{V}_{d}=\left\{(m . i): m \in M_{d}^{\wedge} i \in I_{d}\right\}
$$$$
\breve{V}_{s}=\left\{(m . i): m \in M_{s}^{\wedge} i \in I_{s}\right\}
$$ 
We can imagine two types of products for each node. In some constraints, it is necessary to define the relationship between the entity and input products. Therefore, two sets of input products can be defined for factory entities and customers, as follows:

$$
\widehat{V}_{f}=\left\{(m . i): m \in M_{s}^{\wedge} i \in I_{f}\right\} \cup\left\{(m . i): m \in M_{d}^{\wedge} i \in I_{f}\right\} \quad \widehat{V}_{c}=\left\{(m . i): m \in M_{w} \wedge i \in I_{c}\right\}
$$

Also, the set of $\bar{V}=\widehat{V}_{f} \cup \breve{V}_{w} \cup \breve{V}_{d} \cup \breve{V}_{c}$ is required to define the objective function. The flows in graph are connector of the different nodes of the chain that are defined by the entity-entity pair. The model has 5 levels, which are defined as a result of the flow:

$$
\begin{array}{ll}
A_{f w}: A_{f 1}=\left\{(i . j): i \in I_{f} \wedge j \in I_{w}\right\} & A_{c d}: A_{d 1}=\left\{(i . j): i \in I_{c} \wedge j \in I_{d}\right\} \\
A_{w c}: A_{f 2}=\left\{(i . j): i \in I_{w} \wedge j \in I_{c}\right\} & A_{d f}: A_{d 2}=\left\{(i . j): i \in I_{d} \wedge j \in I_{f}\right\}
\end{array}
$$

Consider all network flows as $A$ with $A=\cup_{k \in K}^{K} A_{k}$ and $K=\left\{f_{1} \cdot f_{2} \cdot d_{1} \cdot d_{2}\right\}$. The suppliers and disposal centers are two other parts of this model that a virtual entity is considered for each with that can be shown a flow between them. $A_{s}=\left\{(i . j): i \in Y_{s} \wedge j \in I_{f}\right\}$ and $A_{o}=\left\{(i . j): i \in I_{d} \wedge j \in I_{o}\right\}$ which are considered for the supplier and disposal center, respectively. The flow of the supplier is modeled as a flow of dummy entity, and the flow of the disposal center is modeled as a flow from each separation center to a disposal center. Like entities, flows can also be defined as developed considering products. As previously mentioned, each flow is related to a product, and so the following set can be defined:

$$
\begin{array}{ll}
F_{f 1}=\left\{(m . i . j): m \in M_{f}^{\wedge}(i . j) \in A_{f 1}\right\} & F_{d 1}=\left\{(m . i . j): m \in M_{c}^{\wedge}(i . j) \in A_{d 1}\right\} \\
F_{f 2}=\left\{(m . i . j): m \in M_{w}^{\wedge}(i . j) \in A_{f 2}\right\} & F_{d 2}=\left\{(m . i . j): m \in M_{d} \wedge(i . j) \in A_{d 2}\right\}
\end{array}
$$

And with adding the supplier and the disposal center, the following two sets are also added:

$$
F_{d}=\left\{(m . i . j): m \in M_{d}^{\wedge}(i . j) \in A_{o}\right\} \quad F_{s}=\left\{(m . i . j): m \in M_{s}^{\wedge}(i . j) \in A_{s}\right\}
$$

Consider $\mathrm{t}$ and $\mathrm{t}^{\prime}$ as short time period (micro) and long time period (macro). We define two sets of $\mathrm{t}$ and $\mathrm{t}^{\prime}$ as follow:

$T=\left\{t_{1}, t_{2}, \ldots, t_{n}\right\}, T^{\prime}=\left\{t^{\prime}{ }_{1}, t^{\prime} 2, \ldots, t^{\prime}{ }_{n}\right\}$ and $\bar{T}=\left\{\left(t . t^{\prime}\right): t \in T^{\wedge} t^{\prime} \in T^{\prime}\right\}$

The parameters of the model are as follows:

$\tau_{i j}$ : required travel time between two entities $i$ and $j$,

$\emptyset_{m}$ : The time of production process for product $m$,

$\gamma_{m i}$ : the time of travel and process that its result is earliest short time for product flow $\mathrm{m} \in \mathrm{M}$.

The scenarios are defined as follows:

$\mathrm{R}$ : The return category levels of final product where $r \in M$ (as optimistic and pessimistic),

$\mathrm{G}$ : the output of separation and sorting process with $\mathrm{g} \in G$,

Q: Qualitative categorization of products as a result of the sorting process when $\mathrm{q} \in Q$

The model independent parameters of time as follows:

$\alpha_{m}$ : Recycling target for the product $\mathrm{m}, \alpha_{m} \in[0.1]$

$\beta_{m \bar{m}}$ : Relationship between product $\mathrm{m}$ and $\bar{m}$

$S_{m i 0}$ : The primary inventory of product (m) in entity $i$ where $i \in I$

$f_{i}$ : The cost of building the entity $i$

$c_{i}$ : The cost of losing a potential customer $i$

$g_{i}^{P}$ and $h_{i}^{p}$ : Maximum and minimum supply level of entity $i$

$g_{i}^{S}$ : Maximum storage capacity for the entity $i$

$P_{g}$ : The possibility of $g$ output for the ranking process

$P_{r}$ : The possibility of occurring $r$ output for return level

$C_{0}$ : The purchase price per unit of raw material $\mathrm{M}$ in the factories

$R f_{r m}$ : Return ratio for the final product $m \in M_{c}$ at level $r$. 
The model Time-related parameters as follows:

$c s l_{i t}$ : The response level for customer $i\left(i \in I_{c}\right)$ at time $t$

$d_{\text {mit }}$ : The demand of product $m$ in entity $i$ at the period of $i \in I_{c}$

$C_{m i \bar{t}}^{S}$ : The warehousing cost of entity $i$ at time $t$

$\vartheta_{m \bar{t}}$ : The price of product $m\left(m \in M_{w}\right)$ at time $t$

$C_{m i t}^{u}$ : The variable cost of returned product $m$ to entity $i \in I_{c}$ at time $t$

$C_{m i j \bar{t}}$ : The transportation cost of product $m$ from entity $i$ to entity $j$ at time $t$

$c r_{q m i j \bar{t}}$ : The quality category cost of returned products $\mathrm{m}$ from entity $i$ to entity $j$ at time $t$

$f r_{\text {gqmijit }}$ : The quality category ratio in category $g$ from product $m$ from entity $i$ to entity $j$ at time $t$.

The continuous variables of model are as follows:

$X_{\text {rgmijit }}$ : The amount of product $m$ which was carried from entity $i$ to entity $j$ at time $t$ under the scenario $(r, g)$ with the return rate $r$ and category $g$,

$S_{\text {rgmit }}$ : The amount of product $\mathrm{m}$ that is stored in entity $i$ at time $t$ under the scenario $(r, g)$,

$U_{\text {rgmit }}$ : The amount of unsatisfied demand for the product $m$ for the customer $i$ at time $t$ under the scenario $(r, g)$,

$Y_{i}$ : Zero and none zero variable for building entity $i$.

\section{Model Formulation}

The multi-period, multi-product Mixed Integer Linear Programming (MILP) of Salema et al. (2010) is provided in this section which is one of the most common frameworks of stochastic programming. In this model, the uncertainty is considered through a set of independent scenarios representing how the performance will be different during planning period according to the limits of the quality level and the returned products. Therefore, a possibility is assigned to occur of each scenario. In the scenario-based approach, the uncertainty caused by the number of returned products from customers to the separation centers is considered as $R$ that is the possibility of occurring is $\mathrm{P}_{\mathrm{r}}$. Each of these states represents a certain volume of returned product or a certain ratio of the final product. On the other hand, the second uncertainty factor is the returns which is obtained in the separation centers and are delivered to the factory and can be expressed in $Q$ different categories. For example, it can be assumed that inputs are categorized based on three different groups: good, medium, and bad. Therefore, the quality of the returned products sent to the factory is a combination of these three categories with different percentages that is attributed it with uncertainty and are definable as an independent outputs $G$ where $P_{g}$ is the possibility of occurring each of states. The proposed approach defines scenarios for combining the independent points $r$ and $g$ where $(\Omega=\{(r . g)\})$, where the possibility of each scenario is $\mathrm{P}_{\mathrm{r} v} \vee \mathrm{P}_{\mathrm{g}}$ according to their independence, because the source of the two types of uncertainty has been considered independent. The considered objective function is to maximize the total profit of the supply chain (Eq. 1). In the following, we review the equations that form the objective function:

The costs of establishing of the facility including factories, warehouses, separation centers and disposal centers. In this model, the penalty cost is significant from lost customer. Like the first one, this cost is independent from scenarios and is considered as first-level cost. The transportation cost is a secondlevel cost that will be related to the selected scenario and is displayed in the model with the possibility of the scenario. The forth cost is related to the categorized products which are delivered to a factory. The penalty cost is a ratio of the demand in the fifth sentence and the penalty cost for any inventory is in any entity other than the customer (sixth sentence), which will not be included $\breve{V}_{c}$. The seventh part is for the cost of supplying raw materials from the supplier $\mathrm{Y}_{0}$ in the factories because the amount of recycled goods is not always enough for consumption in subsequent periods and the factory is forced to supply raw materials. The eighth part is the revenue obtained from selling the final product delivered 
to customers under scenarios and for this reason, it is considered with multiplication of the possibility of occurring the scenario in the model.

$$
\begin{aligned}
\operatorname{Max} F=- & \sum_{(r . g) \in \Omega} P_{r} P_{g}\left(\sum_{m i j:(m i j) \in F \backslash F_{d 2}} \sum_{\bar{t}\left(t . t^{\prime}\right) \in \bar{T}} c_{m i j \bar{t}} X_{r g m i j \bar{t}}\right. \\
& +\sum_{m i j:(m . i . j) \in F_{d 2}} \sum_{t:\left(t . t^{\prime}\right) \in \bar{T}} \sum_{q \in Q} c r_{q m i j \bar{t}} f r_{g q m i j \bar{t}} X_{r g m i j \bar{t}} \\
& +\sum_{m i:(m . i) \in \widehat{V}_{c}} \sum_{t \in T}^{c_{m i t}^{u}} U_{r g m i t}+\sum_{m i:(m . i) \in \bar{V}} \sum_{\backslash \breve{V}_{c} \bar{t}:\left(t . t^{\prime}\right) \in \bar{T}} c_{m i \bar{t}}^{S} S_{r g m i \bar{t}} \\
& \left.+\sum_{m i j:(m i j) \in F_{s}} \sum_{\bar{t}:\left(t . t^{\prime}\right) \in \bar{T}} c_{0} X_{r g m i j \bar{t}}\right)-\sum_{i \in I} f_{i} Y_{i}-\sum_{m i:(m . i) \in \widehat{V}_{c}} \sum_{t \in T} \llbracket c_{i} d_{m i t}(1-Y \rrbracket)
\end{aligned}
$$

The constraints are similar to Salema et al. (2010) that have been determined for each scenario $(r, g)$. The Eqs. (2-5) guarantee the balance of materials in the entities by examining the flow and output equivalence plus the difference between the initial and final inventory of the period. Thus, the first constraint is defined as follows (Eq. (2) for factory, Eq. (3) for warehouses, Eq. (4) for costumers and Eq. (5) for separation centers):

$$
\begin{aligned}
& S_{r g m i \gamma\left(t . t^{\prime}-1\right)}+\sum_{\bar{m} j:(\bar{m} . j . i) \in F_{d 2}} R f_{r \bar{m}} \beta_{m \bar{m}} X_{r g \bar{m} j i \gamma\left(t . t^{\prime}-\tau_{j i}-\emptyset_{m}\right)}+\sum_{\bar{m} j:(\bar{m} . j . i) \in F_{S}} \beta_{m \bar{m}} X_{r g \bar{m} j i \gamma\left(t . t^{\prime}\right)}= \\
& \sum_{m i:(m . i . j) \in F_{f 1}} X_{r g m i j \bar{t}}+S_{r g m i \bar{t}} \text {. } \\
& (r . g) \in \Omega \wedge(\bar{m} . i) \in \widehat{V}_{f} \wedge(m . i) \in \breve{V}_{f} \wedge \bar{t}:\left(t . t^{\prime}\right) \\
& S_{r g m i \gamma\left(t . t^{\prime}-1\right)}+\sum_{\bar{m} j:(\bar{m} . j . i) \in F_{f 1}} R f_{r \bar{m}} \beta_{m \bar{m}} X_{r g \bar{m}} j i \gamma\left(t . t^{\prime}-\tau_{j i}-\emptyset_{m}\right)= \\
& \sum_{m i:(m . i . j) \in F_{f 2}} X_{r g m i j \bar{t}}+S_{r g m i \bar{t}} \text {. } \\
& (r . g) \in \Omega \wedge(\bar{m} . i) \in \widehat{V}_{w} \wedge(m . i) \in \breve{V}_{w} \wedge \bar{t}:\left(t . t^{\prime}\right) \\
& \sum_{\bar{m} j:(\bar{m} . j . i) \in F_{f 2}} R f_{r \bar{m}} \beta_{m \bar{m}} X_{r g \bar{m} j i \gamma\left(t . t^{\prime}-\tau_{j i}-\emptyset_{m}\right)}=\sum_{m i:(m . i . j) \in F_{d 1}} X_{r g m i j \bar{t}} \\
& (r . g) \in \Omega \wedge(\bar{m} . i) \in \widehat{V}_{c} \wedge(m . i) \in \breve{V}_{c} \wedge \bar{t}:\left(t . t^{\prime}\right) \\
& S_{\text {rgmir }\left(t . t^{\prime}-1\right)}+\sum_{\left.\bar{m} j \Theta \bar{m}_{j} . i\right) \in F_{d 1}} R f_{r \bar{m}} \beta_{m \bar{m}} X_{r g \bar{m} j i \gamma\left(t . t^{\prime}-\tau_{j i} \emptyset_{m}\right)}= \\
& \sum_{m i:(m i . j) \in F_{d 2}} X_{\text {rgmije }}+S_{\text {rgmi }} \text {. } \\
& (r . g) \in \Omega \wedge(\bar{m} . i) \in \widehat{V}_{d} \wedge(m . i) \in \breve{V}_{d} \wedge \bar{t}:\left(t . t^{\prime}\right)
\end{aligned}
$$

Eq. (6) is related to the customer's demand category that has a specific demand in time period. The unsatisfied amount of demand is shown in variable of $U$. Finally, this limitation satisfies the demand when customers are selected to enter the network:

$$
\begin{aligned}
& \sum_{j:(m . j . i) \in F_{f 2}} \sum_{t \prime \in T} X_{r g m j i \gamma\left(t . t^{\prime}-\tau_{j i}\right)}+U_{r g m i t}=d_{m i t} Y_{i} . \\
& (r . g) \in \Omega \wedge(m . i) \in \widehat{V}_{c} \wedge t \in T
\end{aligned}
$$

The constraint 6 applies the minimum rate of customer's satisfaction. So, the amount of delivered product to customer $i$ must be greater than or equal to $\operatorname{csl}_{i t}$ during the macro period $\bar{t}$.

$$
\sum_{m j:(m . j . i) \in F_{f 2}} \sum_{t \prime \in T} X_{r g m j i \gamma\left(t . t^{\prime}-\tau_{j i}\right)} \geq c s l_{i t} \sum_{m \in M_{w}} d_{m i t} Y_{i}, \quad(r . g) \in \Omega \wedge i \in I_{c} \wedge t \in T
$$

The Eq. (8) considers the legal restrictions for recycling. Parameter $\alpha_{\mathrm{m}}$ is the minimum rate of recycling for product $m$, which has been expressed by environmental policies. Therefore, disassembly centers can only dispose less than $1-\alpha_{m}$ of the collected products.

$$
\begin{aligned}
& \sum_{j \in I_{o}} \sum_{t \prime \in T}, X_{r g m i j \gamma\left(t . t^{\prime}\right)} \leq\left(1-\alpha_{m}\right) \sum_{m j:(m . j . i) \in F_{d 1}} * \sum_{t \prime \in T} \beta_{m \bar{m}} X_{r g m i j \gamma\left(t . t^{\prime}-\tau_{j i}\right)} \quad,(r . g) \in \\
& \Omega \wedge(m . i) \in \breve{V}_{d} \wedge t \in T
\end{aligned}
$$

Eqs. (9)-(14) represent the lower and upper bounded of supply, which are also stated in most contracts. These amounts can be considered different for each factory to be aligned with managerial policies.

$$
\begin{aligned}
& \sum_{m j:(m . i . j) \in F_{f 1}} X_{r g m j i \bar{t}} \leq g_{i}^{p} Y_{i},(r . g) \in \Omega \wedge(i . j) \in A_{f 1} \wedge \bar{t}:\left(t . t^{\prime}\right) \in \bar{T} \\
& \sum_{m j:(m . i . j) \in F_{f 1}} X_{r g m i j \bar{t}} \geq h_{i}^{p} Y_{i},(r . g) \in \Omega \wedge(i . j) \in A_{f 1} \wedge \bar{t}:\left(t . t^{\prime}\right) \in \bar{T} \\
& \sum_{m j:(m . i . j) \in F_{f 2}} X_{r g m j i \bar{t}} \leq g_{i}^{p} Y_{i},(r . g) \in \Omega \wedge(i . j) \in A_{f 2} \wedge \bar{t}:\left(t . t^{\prime}\right) \in \bar{T}
\end{aligned}
$$


$\sum_{m j:(m . i . j) \in F_{f 2}} X_{r g m i j \bar{t}} \geq h_{i}^{p} Y_{i},(r . g) \in \Omega \wedge(i . j) \in A_{f 2} \wedge \bar{t}:\left(t . t^{\prime}\right) \in \bar{T}$

$\sum_{m j:(m . i . j) \in F_{d 2}} X_{r g m j i \bar{t}} \leq g_{i}^{p} Y_{i},(r . g) \in \Omega \wedge(i . j) \in A_{d 21} \wedge \bar{t}:\left(t . t^{\prime}\right) \in \bar{T}$

$\sum_{m j:(m . i . j) \in F_{d 2}} X_{r g m i j \bar{t}} \geq h_{i}^{p} Y_{i},(r . g) \in \Omega \wedge(i . j) \in A_{d 2} \wedge \bar{t}:\left(t . t^{\prime}\right) \in \bar{T}$

Eq. (15) restricts the capacity of facilities, warehouses, and categorization centers.

$\sum_{m:(m . i) \in \bar{V} / \breve{V}_{c}} S_{r g m i \bar{t}} \leq g_{i}^{s} Y_{j},,(r . g) \in \Omega \wedge i \in I \wedge \bar{t}:\left(t . t^{\prime}\right) \in \bar{T}$

\section{Numerical Example}

Nowadays, the crude steel production is performed in two main ways: first, providing melted iron in the furnace and steel production in oxygen converters and second, melting the scrap or sponge iron in electric arc furnaces. Scrap iron is directly converted into steel in electric arc furnace method. In Iran, $28.8 \%$ of crude steel production process is performed using blast furnace and oxygen convertor and $71.2 \%$ by electric arc furnace method. There is no clear information about the conditions and the consumption rate of iron scrap in Iran's steel production, but according to $20 \%$ consumption coefficient of scrap iron in steel production in the operating units, there is a need to produce an estimated amount of 12 billion tons of scrap iron where it can be seen the need for grounding and creating the appropriate conditions for recycling scrap iron and it is necessary to make a special planning to provide the required infrastructure for collecting the scrap metal. In this study, a schematic diagram is applied to represent the proposed CLSC structure, which is used from factory to customer and return from the customer to the factory. Each node represents an entity in the supply chain (such as a factory, warehouse, customer, etc.), and each vector between the two nodes represents the current flow between the two entities. The proposed CLSC structure includes five potential points for building a factory, warehouse, recycling center, disposal center and potential customer. The factories receive two raw materials $\left(\mathrm{M}_{1}\right.$ and $\left.\mathrm{M}_{2}\right)$ for producing three different product types $\left(\mathrm{F}_{1}, \mathrm{~F}_{2}, \mathrm{~F}_{3}\right)$, and these products are sent to warehouses where other operations are performed, such as deformation, etc. and eventually, is resulted in six final products ( $A_{1}$ to $A_{6}$ ). Customers actually purchase these final products. As a result, demand for each product will vary in terms of customers. Table 2 illustrates the demand of each customer for product $A_{1}$ as an example in the first half of the planning period.

\section{Table 2}

Demand of each customer for product $\mathrm{A}_{1}$ over time periods

\begin{tabular}{|c|c|c|c|c|c|c|c|c|c|c|c|}
\hline \multirow{2}{*}{ Product } & \multirow{2}{*}{$\begin{array}{l}\text { Customer } \\
\text { ID }\end{array}$} & \multicolumn{10}{|c|}{ Time Periods } \\
\hline & & T1 & $\mathrm{T} 2$ & T3 & $\mathrm{T} 4$ & T5 & T6 & T7 & T8 & T9 & $\mathrm{T} 10$ \\
\hline A1 & I01 & 187563 & 188832 & 200107 & 201388 & 203787 & 205080 & 206270 & 206575 & 207888 & 200207 \\
\hline A1 & I02 & 107034 & 108213 & 100510 & 100820 & 113257 & 114599 & 114846 & 116220 & 117612 & 110017 \\
\hline A1 & I03 & 300146 & 301204 & 303274 & 305356 & 408559 & 410663 & 411670 & 413807 & 416037 & 418119 \\
\hline A1 & I04 & 63634 & 65420 & 65214 & 66017 & 77940 & 78760 & 78478 & 80317 & 80164 & 81001 \\
\hline A1 & I05 & 468860 & 474004 & 480205 & 484432 & 500716 & 506159 & 500427 & 515855 & 511331 & 516856 \\
\hline
\end{tabular}

A part of the six products will be sent to separation centers by consumers after consumption, each product having its own return ratio. The separation centers categorize returned products with different qualitative levels. It is assumed that the separation centers categorize the returned products into three qualitative categories and they are sent to factories based on the qualitative categorization in order to use in the new product or send to disposal centers, that disposal should not be exceeded from legal limitation. Fig. 1 shows the material flow in this closed-loop supply chain. The quality of the returned products is considered as non-deterministic and with five possible situations: excellent, good, medium, bad and very bad. Each situation is a combination of different qualities, including good, medium and bad that are the results of the categorization process in the separation centers. Table 3 illustrates the possibility of each situation and the percentage of returned products in each qualitative category. 


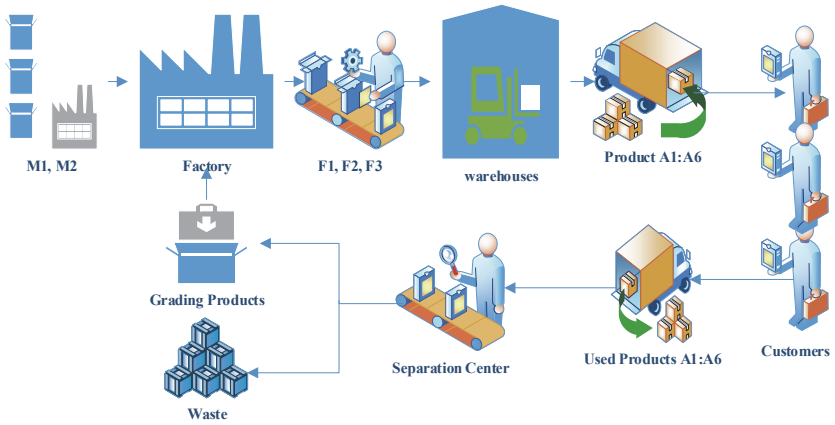

Fig.1.The material flow in the steel closed-loop supply chain

Table 3

The returned products categorization

\begin{tabular}{ccccc}
\hline Output Category & Possibility & Good value & Medium value & Bad value \\
\hline Excellent & 0.12 & 1 & 0 & 0 \\
Good & 0.45 & 67 & 33 & 0 \\
medium & 0.22 & 33 & 33 & 33 \\
Bad & 0.13 & 0 & 67 & 33 \\
very bad & 0.08 & 0 & 0 & 1 \\
\hline
\end{tabular}

As mentioned, the returned product is categorized in the separation centers before sending to the factories. According to that the returned products compete with raw materials for producing the new product, their combination and price will be the critical parameters for the system. Table 4 shows the data by providing the price of raw materials and returned categorized products.

\section{Table 4}

The cost of raw materials and returned product

\begin{tabular}{|c|c|c|c|}
\hline \multicolumn{2}{|c|}{ Cost (\$) } & M1 & M2 \\
\hline \multicolumn{2}{|c|}{ Raw Material } & 7480 & 9420 \\
\hline \multirow{3}{*}{ Returned Products Quality } & Good & 5630 & 8360 \\
\hline & medium & 6980 & 9410 \\
\hline & Bad & 7940 & 10580 \\
\hline
\end{tabular}

The non-deterministic quantity of returned products is estimated at three levels of optimistic (R1), possible (R2) and pessimistic (R3). Table 5 shows the returned ratio of the final products and their possibility of occurrence at each level.

Table 5

Returned product ratio and their possibility of occurrence

\begin{tabular}{ccccccccc}
\hline & & \multicolumn{5}{c}{ Product } \\
\cline { 4 - 8 } & & Possibility & A1 & A2 & A3 & A4 & A5 & A6 \\
\hline \multirow{3}{*}{ Returned ratio } & Optimistic & 0.28 & 0.45 & 0.75 & 0.65 & 0.85 & 0.55 & 0.9 \\
& Possible & 0.43 & 0.40 & 0.65 & 0.60 & 0.7 & 0.45 & 0.85 \\
& Pessimistic & 0.29 & 0.35 & 0.55 & 0.5 & 0.65 & 0.35 & 0.75 \\
\hline
\end{tabular}

Table 6

The price of final product $(\$)$

\begin{tabular}{ccccccccccc}
\hline \multirow{2}{*}{$\begin{array}{c}\text { Product } \\
\text { Type }\end{array}$} & \multicolumn{10}{c}{ Time periods } \\
\cline { 2 - 11 } & T1 & T2 & T3 & T4 & T5 & T6 & T7 & T8 & T9 & T10 \\
\hline A1 & 20270 & 20600 & 20207 & 20207 & 18661 & 18843 & 18845 & 20344 & 20683 & 20309 \\
A2 & 13080 & 14234 & 15010 & 14708 & 14421 & 14421 & 14504 & 14353 & 15030 & 16400 \\
A3 & 14340 & 13841 & 16214 & 15014 & 16010 & 14022 & 14822 & 13710 & 15040 & 14214 \\
A4 & 12400 & 12725 & 13280 & 12156 & 12030 & 10868 & 11017 & 11020 & 10267 & 10207 \\
A5 & 13700 & 13501 & 13800 & 12410 & 12110 & 10500 & 11400 & 10400 & 10850 & 10806 \\
A6 & 13700 & 13610 & 16152 & 15356 & 14502 & 14340 & 15527 & 15840 & 15547 & 15452 \\
\hline
\end{tabular}


Also, Table 6 shows the final products price (A1-A6) in time periods. It should be mentioned that the price of the products is also considered incremental based on the current prices and linear based on prediction function.

\section{Computational results}

Many studies have been conducted to investigate the effects of parameters related to the quality and quantity of returned flow on designing the closed loop supply chain. To describe these effects in the presented model, non-deterministic scenarios and parameters have been considered, simultaneously, that the output of this model in optimal conditions was investigated with actual values and using the Cplex solver of the GAMS software, on a computer with 4 GB internal memory under Windows 10 is performed. Five different scenarios were considered to investigate the effect of different qualitative levels of returned products. Table 7 shows the results of the best scenario of main network for five different scenarios. As it is seen in Table 8, the quality of the returns has a significant effect on maximizing the profits. Therefore, the more profit is obtained when all of returns have got a good quality (G1). The size of the network is decreased by reducing the quality of the returns and get its minimum at the (G5), and finally it leads to minimum the number of customers and separation centers. In the state of G3 to G5, the network structure is largely unchanged, but the chain's profit is heavily influenced by changes in sales and increasing costs.

Table 7

The output of model in optimal conditions

\begin{tabular}{cccccccccccccccccc}
\hline & Optimal Structure & \multicolumn{1}{c}{ G1 } & \multicolumn{1}{c}{ G2 } & \multicolumn{3}{c}{ G3-5 } \\
\hline Customer ID & F & W & C & D & F & W & C & D & F & W & C & D & F & W & C & D \\
I01 & & 1 & 1 & 1 & & 1 & 1 & 1 & & 1 & 1 & 1 & & 1 & 1 \\
I02 & 1 & 1 & & 1 & 1 & 1 & & & 1 & 1 & & & 1 & 1 & \\
I03 & & 1 & 1 & 1 & & & 1 & 1 & & & 1 & 1 & & & \\
I04 & 1 & 1 & 1 & 1 & 1 & 1 & 1 & & 1 & 1 & 1 & & 1 & 1 & 1 & 1 \\
I05 & & 1 & & 1 & & 1 & & 1 & & 1 & & & & 1 & & \\
\hline Total entities & 2 & 5 & 3 & 5 & 2 & 4 & 3 & 3 & 2 & 4 & 3 & 2 & 2 & 3 & 2 & 2 \\
\hline
\end{tabular}

F: Factory, W: Warehouse, C: Collection Center, D: Disposal Center

According to the unsatisfying cost for the customers' demand in this model, the parameter $U$ received different values in different periods, this value used for period T2- T5 as example in the following table for $\mathrm{G} 1$ and the first three products in different customers.

Table 8

The number of customers' unsatisfied demand during periods T2-T5

\begin{tabular}{cccccccc}
\hline Output of separation process & $\begin{array}{c}\text { Returned } \\
\text { category } \\
\text { levels }\end{array}$ & Products & $\begin{array}{c}\text { Customer } \\
\text { ID }\end{array}$ & T2 & T3 & T4 & T5 \\
\hline R1 & G1 & A1 & I01 & 1808317 & 2006568 & 2013640 & 2026528 \\
R1 & G1 & A1 & I03 & 2862043 & 3032740 & 3053481 & 3075405 \\
R1 & G1 & A1 & I04 & 63420877 & 64834606 & 66880637 & 67800080 \\
R1 & G1 & A2 & I01 & 1888317 & 2006568 & 2013640 & 2026528 \\
R1 & G1 & A2 & I03 & 3012043 & 3032740 & 3053481 & 3074404 \\
R1 & G1 & A2 & I04 & 6442087 & 6483460 & 67860837 & 6580108 \\
R1 & G1 & A3 & I01 & 1886317 & 2003304 & 2013653 & 2026546 \\
R1 & G1 & A3 & I03 & 3012043 & 3032724 & 3053467 & 3074408 \\
R1 & G1 & A3 & I04 & 644218 & 651635 & 6587063 & 6640325 \\
\hline
\end{tabular}

The variable in this model has 270 numbers for each period. Table 8 indicates an example of a qualitative and quantitative level of returned products for three products (A1, A2, A3), and three customers (I01, I03, I04). According to the model's assumptions about the possibility of maintaining the product in the end of the period in all entities (except the customer), Table 9 represents the ending inventory of two different entities. This variable will receive 615 value for each period in model. 
Table 9

The amount of inventory at the end of the period during periods 2 to 5

\begin{tabular}{|c|c|c|c|c|c|c|c|c|}
\hline & & & & & $\mathrm{T} 2$ & T3 & $\mathrm{T} 4$ & T5 \\
\hline R1 & G1 & M1 & I01 & $\mathrm{D}$ & 6000 & & & 6000 \\
\hline R1 & G1 & M1 & I02 & D & 6000 & & & 6000 \\
\hline R1 & G1 & M1 & I03 & D & 6000 & & & 6000 \\
\hline R1 & G1 & M1 & I04 & D & 6000 & & & 6000 \\
\hline R1 & G1 & M1 & I05 & D & 6000 & & & 6000 \\
\hline R1 & G2 & $\mathrm{F} 1$ & I02 & $\mathrm{F}$ & 6000 & & 6000 & 1425.4 \\
\hline R1 & G2 & F1 & I04 & F & 6000 & & 6000 & 517.4 \\
\hline R1 & G2 & F2 & $\mathrm{I} 02$ & $\mathrm{~F}$ & 6000 & 6000 & & 506.4 \\
\hline R1 & G2 & F2 & I04 & F & 6000 & 6000 & & 1207.2 \\
\hline R1 & G2 & F3 & I02 & F & 6000 & & 5374.6 & 6000 \\
\hline $\mathrm{R} 1$ & $\mathrm{G} 2$ & F3 & I04 & $\mathrm{F}$ & 6000 & & 3482.4 & 6000 \\
\hline
\end{tabular}

R: Output of separation process, G: Returned category levels, F: Factory I0: Customer ID, D: Disposal Center, M: Raw Material Type, $F_{\mathrm{i}}$ : Final Product Type

In this model, the parameter $X$ is introduced as the number of moved products between entities. Table 10 shows the amount of moved goods between the factory and warehouse from one qualitative and quantitative returned level, three products and in a period T1-T5.

Table 10

The amount of moved product between entities within periods 2 to 5

\begin{tabular}{|c|c|c|c|c|c|c|c|c|c|c|c|}
\hline \multicolumn{7}{|c|}{ Model Parameters } & $\mathrm{T} 1$ & $\mathrm{~T} 2$ & $\mathrm{~T} 3$ & T4 & $\mathrm{T} 5$ \\
\hline R1 & G1 & F1 & I02 & I01 & $\mathrm{F}$ & $\mathrm{W}$ & 2000 & & 2000 & & \\
\hline R1 & G1 & F1 & I02 & I02 & $\mathrm{F}$ & $\mathrm{W}$ & 2000 & 800000 & 3000 & 3000 & \\
\hline R1 & G1 & F1 & I02 & I03 & $\mathrm{F}$ & $\mathrm{W}$ & & & & 2000 & \\
\hline R1 & G1 & $\mathrm{F} 1$ & $\mathrm{I} 02$ & I05 & $\mathrm{F}$ & W & 2000 & & & & \\
\hline R1 & G1 & F1 & I04 & I01 & $\mathrm{F}$ & W & & & & & \\
\hline R1 & G1 & F1 & I04 & I03 & $\mathrm{F}$ & W & & & & & \\
\hline R1 & G1 & F1 & I04 & I04 & $\mathrm{F}$ & $\mathrm{W}$ & 4000 & 754500 & 178380 & 36458 & 3516 \\
\hline R1 & G1 & $\mathrm{F} 2$ & I02 & I01 & $\mathrm{F}$ & W & & & & & 2000 \\
\hline $\mathrm{R} 1$ & G1 & $\mathrm{F} 2$ & I02 & I02 & $\mathrm{F}$ & W & & 897667 & 900 & & 4000 \\
\hline R1 & G1 & F2 & I02 & I03 & $\mathrm{F}$ & W & 4000 & 4322 & 2000 & & 2000 \\
\hline R1 & G1 & F2 & I02 & I05 & $\mathrm{F}$ & W & & & 2000 & & 2000 \\
\hline R1 & G1 & F2 & I04 & I01 & $\mathrm{F}$ & W & & 624000 & & & \\
\hline R1 & G1 & F2 & I04 & I04 & $\mathrm{F}$ & W & & 226400 & 178380 & 30458 & 17504 \\
\hline R1 & G1 & F3 & I02 & I01 & $\mathrm{F}$ & W & & & & 2000 & \\
\hline R1 & G1 & F3 & I02 & I02 & $\mathrm{F}$ & W & & 894657 & 6000 & 1500 & 1230 \\
\hline R1 & G1 & F3 & I02 & I03 & $\mathrm{F}$ & W & & & & & \\
\hline R1 & G1 & F3 & I02 & I05 & F & W & & 4323 & & 2000 & \\
\hline R1 & G1 & F3 & I04 & I01 & $\mathrm{F}$ & W & & 754600 & & & \\
\hline R1 & G1 & F3 & I04 & I04 & $\mathrm{F}$ & W & & & 178380 & 36457 & 5404 \\
\hline
\end{tabular}

R: Output of separation process, G: Returned category levels, F: Factory I0: Customer ID, W: Warehouse, Fi: Final Product Type

\section{Conclusion and suggestions}

In this paper, a scenario-based approach has been provided to overcome the uncertainty in the quantity and quality of returned products for designing a closed-loop supply chain. The strength of this study is to integrate two major sources of uncertainty simultaneously, combined with a better insight from the returning flow characteristics, and the consideration of variable demand during the time horizon. Formulation of the model evaluated by a real case in the steel industry and its numerical results have been presented in the previous section. From the obtained results in the model, it can be concluded that by increasing the quality level of returned products (from $\mathrm{g} 5$ to g1) the need for raw materials was reduced and increased the total profit of the chain. By increasing the number of returned products, due to increase operational costs (and the need to build new facilities), the rate of profitability was reduced, which can make the chain unprofitable at high levels of returned products. As a suggestion for further 
research, we may use heuristic algorithms to decrease the number of parameters in the proposed model and we leave it as a future studies.

\section{References}

Adenso-Díaz, B., Moreno, P., Gutiérrez, E., \& Lozano, S. (2012). An analysis of the main factors affecting bullwhip in reverse supply chains. International Journal of Production Economics, 135(2), 917-928.

Akcali, E., \& Cetinkaya, S. (2011). Quantitative models for inventory and production planning in closed-loop supply chains. International Journal of Production Research, 49(8), 2373-2407.

Alamdar, S., Rabbani, M., \& Heydari, J. (2019). Optimal decision problem in a three-level closed-loop supply chain with risk-averse players under demand uncertainty. Uncertain Supply Chain Management, 7(2), 351-368.

Amin, S. H., \& Baki, F. (2017). A facility location model for global closed-loop supply chain network design. Applied Mathematical Modelling, 41, 316-330.

Amin, S. H., \& Zhang, G. (2013). A multi-objective facility location model for closed loop supply chain network under uncertain demand and return. Applied Mathematical Modelling, 37(6), 41654176.

Amin, S. H., Zhang, G., \& Akhtar, P. (2017). Effects of uncertainty on a tire closed-loop supply chain network. Expert Systems with Applications, 73, 82-91.

Cannella, S., Bruccoleri, M., \& Framinan, J. M. (2016). Closed-loop supply chains: What reverse logistics factors influence performance. International Journal of Production Economics, 175, 3549.

Cardoso, S., Barbosa-Póvoa, A. P. F. D., \& Relvas, S. (2013). Design and planning of supply chains with integration of reverse logistics activities under demand uncertainty. European Journal of Operations Research, 226(3), 436-451.

Chen, S. P., \& Chang, P. C. (2006). A mathematical programming approach to supply chain models with fuzzy parameters. Engineering Optimization, 38, 647-669.

Darbari, J. D., Kannan, D., Agarwal, V., \& Jha, P. C. (2017). Fuzzy criteria programming approach for optimising the TBL performance of closed loop supply chain network design problem. Annals of Operations Research, 1-46.

Denizel, M., Ferguson, M., \& Souza, G. (2010). Multiperiod remanufacturing planning with uncertain quality of inputs. IEEE Transactions on Engineering Management, 57(3), 394-404.

Dowlatshahi, S. H. A. D. (2010). A cost-benefit analysis for the design and implementation of reverse logistics systems: case studies approach. International Journal of Production Research, 48(5), 1361-1380.

Ene, S., \& Öztürk, N. (2017). Grey modelling-based forecasting system for return flow of end-of-life vehicles. Technological Forecasting and Social Change, 115, 155-166.

Farrokh, M., Azar, A., Jandaghi, G., \& Ahmadi, E. (2018). A novel robust fuzzy stochastic programming for closed loop supply chain network design under hybrid uncertainty. Fuzzy Sets and Systems, 341, 69-91.

Gaur, J., Amini, M., \& Rao, A. K. (2017). Closed-loop supply chain configuration for new and reconditioned products: An integrated optimization model. Omega, 66, 212-223.

Ghassemi, A., Asl-Najafi, J., \& Yaghoubi, S. (2018). A dynamic bi-objective closed-loop supply chain network design considering supplier selection and remanufacturer subcontractors. Uncertain Supply Chain Management, 6(2), 117-134.

Govindan, K., \& Soleimani, H. (2017). A review of reverse logistics and closed-loop supply chains: A Journal of Cleaner Production focus. Journal of Cleaner Production, 142, 371-384.

Gupta, A., \& Maranas, C. D. (2003). Managing demand uncertainty in supply chain planning. Computers and Chemical Engineering, 27(8-9), 1219-1227.

He, Y. (2015). Acquisition pricing and remanufacturing decisions in a closed-loop supply chain. International Journal of Production Economics, 163, 48-60. 
Jeihoonian, M., Zanjani, M. K., \& Gendreau, M. (2017). Closed-loop supply chain network design under uncertain quality status: Case of durable products. International Journal of Production Economics, 183, 470-486.

Kadambala, D. K., Subramanian, N., Tiwari, M. K., Abdulrahman, M., \& Liu, C. (2017). Closed loop supply chain networks: Designs for energy and time value efficiency. International Journal of Production Economics, 183, 382-393.

Klibi, W., Martel, A., \& Guitouni, A. (2010). The design of robust value-creating supply chain networks: a critical review. European Journal of Operational Research, 203(2), 283-293.

Lee, D., \& Dong, M. (2009). Dynamic network design for reverse logistics operations under uncertainty. Transportation Research Part E: Logistics and Transportation Review, 45(1), 61-71.

Li, Z., \& Ierapetritou, M. G. (2008). Process scheduling under uncertainty: Review and challenges. Computers and Chemical Engineering, 32(4-5), 715-727.

Masmoudi, M. (2011). Forecasting returns in reverse logistics: application to catalog and mail-order retailing. In International Conference on Industrial Engineering and Systems Management (Vol. 1, No. 1, pp. 507-516).

Masoudipour, E., Amirian, H., \& Sahraeian, R. (2017). A novel closed-loop supply chain based on the quality of returned products. Journal of Cleaner Production, 151, 344-355.

Mohammed, F., Selim, S. Z., Hassan, A., \& Syed, M. N. (2017). Multi-period planning of closed-loop supply chain with carbon policies under uncertainty. Transportation Research Part D: Transport and Environment, 51, 146-172.

Özceylan, E., Demirel, N., Çetinkaya, C., \& Demirel, E. (2017). A closed-loop supply chain network design for automotive industry in Turkey. Computers \& Industrial Engineering, 113, 727-745.

Papageorgiou, L. G. (2009). Supply chain optimization for the process industries: Advances and opportunities. Computers and Chemical Engineering, 33(12),1931-1938.

Pishvaee, M., \& Rabbani, M. (2011). A robust optimization approach to closed-loop supply chain network design under uncertainty. Applied Mathematical Modelling, 35(1), 637-649.

Sahinidis, N. V. (2004). Optimization under uncertainty: State-of-the-art and opportunity. Computers and Chemical Engineering, 28(6-7), 971-983.

Salema, M. I. G., Barbosa-Povoa, A. P., \& Novais, A. Q. (2010). Simultaneous design and planning of supply chains with reverse flows: A generic modeling framework. European Journal of Operational Research, 203(2), 336-349.

Salema, M., Barbosa-Póvoa, A., \& Novais, A. Q. (2007). An optimization model for the design for a capacitated multi-product reverse logistics networks with uncertainty. European Journal of Operations Research, 179, 1063-1077.

Soleimani, H., Govindan, K., Saghafi, H., \& Jafari, H. (2017). Fuzzy multi-objective sustainable and green closed-loop supply chain network design. Computers \& Industrial Engineering, 109, 191-203.

Soleimani, H., Kumar, D. T., \& Kannan, G. (2014). Forecasting return products in an integrated forward/reverse supply chain utilizing an ANFIS. International Journal of Applied Mathematics and Computer Science, 24(3), 669-682.

Temur, G. and Bolat, B. (2012). Reverse logistics network design integrated with product return forecasting approach, 17th International Working Seminar on Production Economics, Innsbruck, Austria, pp. 483-497.

Vahdani, B., Tavakkoli-Moghaddam, R., Jolai, F., \& Baboli, A. (2013). Reliable design of a closed loop supply chain network under uncertainty: An interval fuzzy possibilistic chance-constrained model. Engineering Optimization, 45(6), 745-765.

Zeballos, L. J., Méndez, C. A., \& Barbosa-Povoa, A. P. (2018). Integrating decisions of product and closed-loop supply chain design under uncertain return flows. Computers \& Chemical Engineering, 112, 211-238.

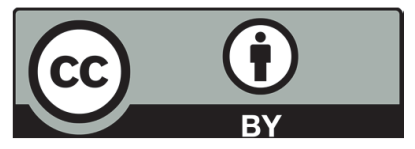

(C) 2019 by the authors; licensee Growing Science, Canada. This is an open access article distributed under the terms and conditions of the Creative Commons Attribution (CC-BY) license (http://creativecommons.org/licenses/by/4.0/). 